\title{
A new bronchoscopic treatment of tracheomediastinal fistula using autologous adipose- derived stem cells
}

\author{
P Díaz-Agero Álvarez, ${ }^{1}$ M García-Arranz, ${ }^{2}$ T Georgiev-Hristov, ${ }^{2}$ D García-Olmo ${ }^{2}$
}

${ }^{1}$ Department of Thoracic Surgery, "La Paz" University Hospital, Universidad Autónoma de Madrid, Madrid, Spain; ${ }^{2}$ Cell Therapy Laboratory-Research Unit, "La Paz" University Hospital, Universidad Autónoma de Madrid, Madrid, Spain

Correspondence to: Dr P Díaz-Agero Álvarez, Thoracic Surgery Unit, Residencia General, Hospital Universitario "La Paz", Paseo de la Castellana 261, 28046

Madrid, Spain; pdiazagero@ gmail.com

PDA and MGA contributed equally to the work described in this manuscript.

Received 7 May 2007 Accepted 2 July 2007

\begin{abstract}
Tracheal fistulas represent a challenging management problem. The standard treatment in most cases is based on surgical procedures. Various endoscopic treatment modalities have been proposed in patients at high surgical risk but the results are often unsatisfactory. The fistulas frequently recur with additional complications and sometimes death. The case history is reported of a patient with a tracheomediastinal fistula resulting from laser treatment of tracheal cancer. The fistula was treated by bronchoscopic injection of autologous adipose-derived stem cells (ASC) suspended in fibrin glue. The patient's stem cells were isolated from lipoaspirate according to a standardised procedure. No complications due to treatment with ASC occurred during the follow-up period and no fistularelated symptoms were detected. Postoperative bronchoscopic examination of the wall and base of the fistula revealed re-epithelialisation and neovascularisation that led to successful closure. To our knowledge, this is the first report of treatment of tracheal fistula by autologous cell therapy. Further studies are needed to confirm whether this new method should become routine practice.
\end{abstract}

Acquired fistulas of the tracheobronchial airway are associated with serious management problems, with high rates of morbidity and mortality. The standard treatment varies with the type of fistula. ${ }^{1}$ The therapeutic approach is individualised and is based on surgical closure or endoscopic techniques. ${ }^{2}$ However, many patients die from haemorrhage resulting from progression of the fistula into the blood vessels. ${ }^{3-5}$ Using our clinical experience with adipose-derived stem cells (ASC), ${ }^{6}$ we attempted to develop a new treatment for tracheomediastinal fistula.

\section{CASE REPORT}

A 67-year-old man with non-small cell lung cancer (T4N2Mx) located in the trachea and upper right lobe was treated initially with radio-chemotherapy and laser irradiation delivered locally through a rigid bronchoscope. During control bronchoscopy performed 2 years after the first treatment, the cancer was found to have reappeared near the carina. The relapse was treated with an Nd-YAG laser (total energy $8450 \mathrm{~J}$ over $40 \mathrm{~min}$ ), applied as three procedures, and chemotherapy. Immediately after this second therapeutic intervention the lasertreated area (anterior tracheal wall) developed progressive necrosis that resulted in a tracheomediastinal fistula. ${ }^{7}$ The diameter of the entrance to the fistula was $10 \mathrm{~mm}$ (fig 1A) and the bronchoscope was able to pass into the mediastinum. Mediastinal tissue and anthracotic lymph nodes were visible. In addition, the right pulmonary artery and the superior vena cava were visible through the thin transparent walls of the fistula. A chest radiograph and CT scan indicated a pretracheal air cavity in the medial mediastinum (fig 1B), communicating through the fistula with the tracheal lumen.

Open surgery was not considered because of the high risk to the patient of surgery in the previously irradiated field. We did consider closing the fistula with a stent or by application of a sealant. ${ }^{2}$ However, a stent would not have reduced the patient's high risk of bleeding from the superior vena cava or the right pulmonary artery, while the sealant might have closed the fistula but would not have promoted healing.

The therapeutic protocol using ASC was presented to and approved by the authorities of the University Hospital "La Paz" according to the requirements of Spanish law. The patient signed a detailed informed consent form prior to the procedure.

\section{Isolation of autologous ASC}

ASC were isolated from a small lipoaspirate $(150 \mathrm{ml})$ according to a published protocol. ${ }^{89}$ The final cell pellet contained $9.8 \times 10^{6}$ cells. Half of them were resuspended in the thrombin component of a fibrin glue kit (Tissucol Duo 2.0; Baxter, Madrid, Spain) prior to combination of the two components. The other half was used for characterisation studies and quantification of the cell growth. The total duration of the process from liposuction to the injection of the cells lasted $<3 \mathrm{~h}$, and the cells were neither cultured nor passed.

\section{Endoscopic treatment and clinical follow-up}

Rigid bronchoscopy was performed under general anaesthesia and jet ventilation. ASC-containing fibrin glue was injected into the cavity of the fistula through a bronchofibroscope.

Postoperative recovery was uneventful with no ventilatory or circulatory complications and no pain. The patient was monitored in hospital for 4 days and discharged without symptoms. A general examination was performed weekly for the first month after surgery. The local status of the fistula was assessed monthly by flexible bronchoscopy for the first 3 months after surgery and then every 3 months. Cytological examination of cells from brush and aspiration biopsies was performed after each bronchoscopy. 
Figure 1 Bronchoscopic and CT images from the region of the fistula. (A) Bronchoscopic image recorded before cell therapy. The fistula can be seen on the anterior tracheal wall which had been totally destroyed after the laser treatment of the tumour. The entrance was about $10 \mathrm{~mm}$ in diameter and the bronchoscope could pass through it. Inset: Anthracotic mediastinal lymph nodes as seen through the wall of the fistula. (B) CT image recorded before cell therapy. The fistula was situated between the trachea and a pretracheal mediastinal cavity with an area of $2 \mathrm{~cm}^{2}$, next to the superior vena cava and pulmonary artery, near the ascending aorta. (C) Bronchoscopic image recorded 1 year after cell therapy. The entrance to the fistula was much smaller (diameter 3-4 mm). Inset: The walls of the fistula were covered with "new" epithelium and vessels as a result of neovascularisation and epithelialisation. (D) CT image from the same region of the fistula 1 year after cell therapy. One year after treatment the cavity had disappeared. (E) CT image from the region of the fistula recorded 1 year after cell therapy. This image is the only one to show remnants of the previous fistulous tract. It is clear that the fistula had closed. ${ }^{*}$, small depression; $\mathrm{VC}$, superior vena cava; $\mathrm{AO} a$, ascending aorta; AOd, descending aorta; PA, right pulmonary artery; LPA, left pulmonary artery.
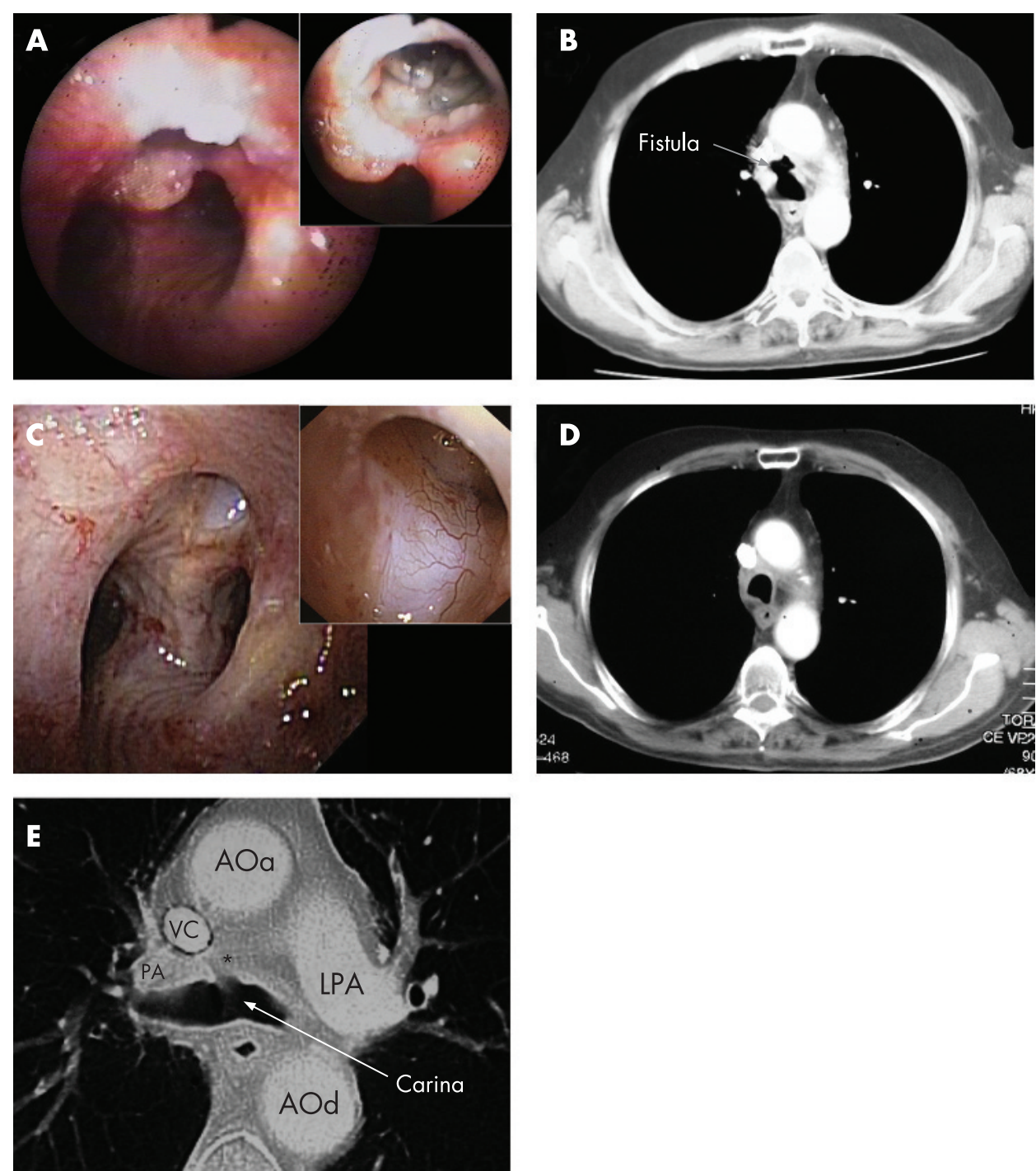

The second bronchoscopy revealed major epithelialisation at the base of the fistula. The new epithelium covered the borders, walls and base of the fistula. Adenopathy became less visible with time and eventually disappeared. In the central region of the base of the fistula, bronchoscopy revealed large amounts of fibroadipose-like connective tissue (fig 1C). These improvements progressed with time and 3 months after the injection of ASC it was impossible to pass the fibroscope through the fistula. One year later, the fistula had closed and was covered with pearly bright epithelium that differed from the surrounding mucosa. We also observed neoangiogenesis in the epithelium. Periodic CT scans revealed disappearance of the initial pretracheal cavity (fig 1D). The only remnant of the fistula was a small depression situated on CT images on the lower margin of the original fistula (fig 1E). No fistula-related symptoms and no treatment-related complications were observed. Four years after the initial diagnosis of cancer and 2 years after stem cell therapy the patient's cancer is in complete remission and he lives a normal life.

\section{DISCUSSION}

Tracheomediastinal fistula is a rare condition that represents a challenging management problem. The new treatment that we propose is based on the use of autologous adult stem cells without culturing. ${ }^{10}$ In this pool of cells there are many different types of cells and only 3-5\% of cells are mesenchymal stem cells (García-Arranz, 2006, unpublished data).

All steps in our novel treatment are relatively easy to perform and present no danger to the patient. Our case represented the worst kind of tracheal fistulous pathology because of the high risks of open surgery and the strong possibility of bleeding during manipulation of the fistula. Nonetheless, the results of treatment were permanent and stable, without any complications during 2 years of follow-up after treatment.

To our knowledge, this is the first report of the use of stem cells derived from adipose tissue for treatment of a tracheomediastinal fistula. Further studies, both in vivo and in vitro, are needed to convert our initial success into a reproducible and reliable treatment for tracheobronchial fistula. Our group has shown that ASC can be used safely for the successful treatment of complex perianal fistulas. ${ }^{6}$ ASC may also prove suitable for the effective treatment of other kinds of fistulas.

Acknowledgements: The authors gratefully acknowledge the support from the Thoracic Surgery and Anaesthesiology Departments of their hospital and, in particular, the Bronchoscopy Unit. They also thank the members of the Cell Therapy Laboratory at the hospital for their work on the isolation, characterization and safe use of stem cells. They are grateful also to Dr Fernando de Miguel for his critical reading of the manuscript.

Funding: This work was supported by Redes Temáticas de Investigación Cooperativa en Salud-Instituto de Salud Carlos III del Ministerio de Sanidad y Consumo de España (RETICS-ISCIII) RD 06/0010/0012. Dr Hristov gratefully acknowledges a fellowship from 
Asociación Española de Cooperación Internacional del Ministerio de Asuntos Exteriores de España (MAE-AECI).

Competing interests: None of the authors has a financial relationship in any commercial entity that has a known interest in the subject of this manuscript.

\section{REFERENCES}

1. Riker Al, Vigneswaran WT. Management of tracheobronchial strictures and fistulas: a report and review of literature. Int Surg 2002;87:114-9.

2. Lois $\mathbf{M}$, Noppen $\mathbf{M}$. Bronchopleural fistulas: an overview of the problem with special focus on endoscopic management. Chest 2005;128:3955-65.

3. Sakamoto J, Hasegawa $\mathrm{S}$, Ito $\mathrm{S}$, et al. A case of broncho-mediastinal fistula with primary lung cancer. J Bronchol 2004;11:42-4.

4. Baydur A, Kanel G. Tracheobronchomalacia and tracheal hemorrhage in patients with Duchenne muscular dystrophy receiving long-term ventilation with uncuffed tracheostomies. Chest 2003;123:1307-11.
5. Dellinger RP, Savage PJ, Carruth $\mathrm{C}$, et al. Tracheocarotid fistula secondary to laryngeal carcinoma presenting as massive hemoptysis. Chest 1983;84:222-4.

6. Garcia-OImo D, Garcia-Arranz M, Herreros LG, et al. A phase I clinical trial of the treatment of Crohn's fistula by adipose mesenchymal stem cell transplantation. Dis Colon Rectum 2005:48:1416-23.

7. Moghissi K, Dixon K, Hudson E, et al. Endoscopic laser therapy in malignant tracheobronchial obstruction using sequential Nd YAG laser and photodynamic therapy. Thorax 1997:52:281-3.

8. Zuk PA, Zhu M, Mizuno $\mathrm{H}$, et al. Multilineage cells from human adipose tissue: implications for cell-based therapies. Tissue Eng 2001;7:211-28.

9. Garcia-Olmo D, Garcia-Arranz M, Garcia LG, et al. Autologous stem cell transplantation for treatment of rectovaginal fistula in perianal Crohn's disease: a new cell-based therapy. Int J Colorectal Dis 2003;18:451-4.

10. Cowan CM, Shi YY, Aalami 00, et al. Adipose-derived adult stromal cells heal critical-size mouse calvarial defects. Nat Biotechnol 2004;22:560-7.

\section{Pulmonary puzzle}

\section{ANSWER}

From the question on $p 359$

After much discussion at the lung cancer multidisciplinary team meeting, the question was jokingly asked "what is he putting down his tracheostomy?" It transpired that the patient suffered with a dry throat from his tracheostomy. Ten years previously he read in "CLAN" (the newsletter of the National Association of Laryngectomee Clubs) that liquid paraffin would solve this. Every night before he went to bed he lay on his back and his wife put three drops of liquid paraffin down his tracheostomy. He went on to explain that he was now getting the paraffin directly from the manufacturer as they had stopped supplying it for medical use some years earlier.

The histology was reviewed confirming a diagnosis of exogenous lipoid pneumonia. He was immediately advised to stop using the paraffin. On follow-up his cough gradually resolved but his chest radiograph remained unchanged. Due to a lack of established treatment options for his condition and his significant co-morbidity, further intervention was deemed inappropriate.

Exogenous lipoid pneumonia results from the inhalation of oil-based substances. Mineral oil depresses the cough reflex favouring aspiration and causes include oil-based laxatives and nasal drops. ${ }^{1}$ Occupational exposure has been described in furniture factories ${ }^{2}$ and steel mills. ${ }^{3}$ Paraffininduced lipoid pneumonia as an occupational hazard of fire-eaters has also been described, ${ }^{4} \mathrm{a}$ condition which has been coined "fire-eater's pneumonia" or "fire-eater's lung".

Cough, weight loss and dyspnoea are the most common symptoms. Radiological features vary from consolidation to nodules and ground-glass opacities. Treatment consists of removal of the offending substance. The use of corticosteroids and partial resection of the lung have been described. ${ }^{2}$ Whole lung lavage has been used as a treatment for endogenous lipoid pneumonia for Niemann-Pick disease $e^{5}$ but its use in exogenous cases is yet to be established.

Thorax 2008;63:376. doi:10.1136/thx.2007.087668a

\section{REFERENCES}

1. Kukafka DS, Kaplan MA, Criner GJ. A 77-year-old man with a lung mass. Chest 1997;111:1439-41.

2. Brown CD, Hewan-Lowe K, Kseibi SA, et al. Exogenous lipoid pneumonia secondary to an occupational exposure in a furniture factory. Chest 2004;126:997S.

3. Cullen MR, Balmes JR, Robins JM, et al. Lipoid pneumonia caused by oil mist exposure from a steel rolling tandem mill. Am J Ind Med 1981;2:51-8.

4. Brander PE, Taskinen E, Stenius-Aarniala B. Fire-eater's lung. Eur Respir J 1992;5:112-4.

5. Nicholson AG, Wells AU, Hooper J, et al. Successful treatment of endogenous lipoid pneumonia due to Niemann-Pick type b disease with whole-lung lavage. Am J Respir Crit Care Med 2002;165:128-31. 